\title{
Natural products against hematological malignancies and identification of their targets
}

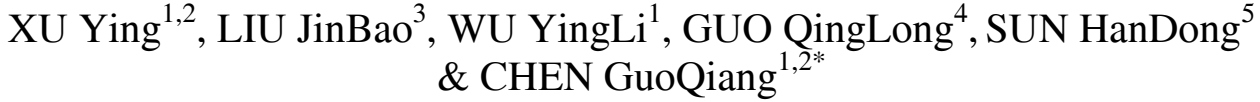 \\ ${ }^{1}$ Department of Pathophysiology, Chemical Biology Division of Shanghai Universities E-Institutes, Key Laboratory of Cell Differentiation and \\ Apoptosis of Ministry of Education, Shanghai Jiao Tong University School of Medicine, Shanghai 200025, China; \\ ${ }^{2}$ Institute of Health Sciences, Shanghai Institutes for Biological Sciences of Chinese Academy of Sciences-Shanghai Jiao Tong University \\ School of Medicine, Shanghai 200025, China; \\ ${ }^{3}$ State Key Laboratory of Respiratory Disease, Protein Modification and Degradation Lab, Department of Pathophysiology, Guangzhou Med- \\ ical University, Guangzhou 510182, China; \\ ${ }^{4}$ State Key Laboratory of Natural Medicines, Jiangsu Key Laboratory of Carcinogenesis and Intervention, China Pharmaceutical University, \\ Nanjing 211198, China \\ ${ }^{5}$ State Key Laboratory of Phytochemistry and Plant Resources in West China, Kunming Institute of Botany, Chinese Academy of Sciences, \\ Kunming 650201, China
}

Received 22 July, 2015; accepted August 16, 2015; published online November 13, 2015

\begin{abstract}
Naturally occurring molecules derived from higher plants, animals, microorganisms and minerals play an important role in the discovery and development of novel therapeutic agents. The identification of molecular targets is of interest to elucidate the mode of action of these compounds, and it may be employed to set up target-based assays and allow structure-activity relationship studies to guide medicinal chemistry efforts toward lead optimization. In recent years, plant-derived natural compounds possessing potential anti-tumor activities have been garnering much interest and efforts are underway to identify their molecular targets. Here, we attempt to summarize the discoveries of several natural compounds with activities against hematological malignancies, such as adenanthin, oridonin, gambogic acid and wogonoside, the identification of their targets, and their modes of actions.
\end{abstract}

natural products, adenanthin, hematological malignancies, target identification

Citation: $\quad$ Xu Y, Liu JB, Wu YL, Guo QL, Sun HD, Chen GQ. Natural products against hematological malignancies and identification of their targets. Sci China Life Sci, 2015, 58: 1191-1201, doi: 10.1007/s11427-015-4922-4

The use of bioactive small molecules, either as single molecular entities or as mixtures, for treating disease is an integral part of human medicine $[1,2]$. Actually, the great reservoir of natural compounds derived from higher plants, animals, microorganisms and minerals demonstrate their important role in the discovery and development of novel therapeutic drugs [3,4]. According to a detailed analysis of new medicines approved by the US Food and Drug Admin-

*Corresponding author (email: chengq@ shsmu.edu.cn; gqchen@sibs.ac.cn) istration (FDA) between 1981 and 2010, about 34\% of these medicines based on small molecules were natural products or direct derivatives of natural products [5]. However, while there is an enormous diversity in the number of plant species (besides animals, microorganisms and minerals) worldwide, less than $10 \%$ have been screened for biological activity, and only $15 \%$ have been phytochemically evaluated. Information concerning the mechanisms of action of bioactive natural products at a molecular level, especially the molecular target(s) of a drug candidate, is of great sig- 
nificance, since it could help set up target-based assays and allow structure-activity relationship studies to guide medicinal chemistry efforts toward lead optimization [1,6]. However, achieving this in an effective, unbiased, and efficient manner is a significant challenge in this new era of drug discovery and optimization [7-9].

Hematological malignancies such as leukemia, lymphomas, and multiple myelomas are a large class of diseases that are characterized by the uncontrolled malignant proliferation, blockade of differentiation and inhibited apoptosis of blood cells [10]. Some of their prominent features include rapid progression and evasion to treatment, thus leading to resistance and relapse. In past decades, rapid development of molecular targeted therapy has been best illustrated by advances in the management of hematological malignancies [11]. For example, several generations of tyrosine kinase inhibitors including imatinib, dasatinib, nilotinib, as well as ponatinib and bosutinib have had a tremendous impact on the clinical outcomes of chronic myeloid leukemia (CML). These compounds act by selectively inhibiting the oncogenic breakpoint cluster region-Abelson (BCR-ABL) fusion protein [12], found in CML cells carrying the chromosome translocation $\mathrm{t}(9 ; 22)$ ( $\mathrm{q} 34 ; 11)$, known as the Philadelphia chromosome, which causes fusion between the $B C R$ and the $A B L$ genes resulting in the expression of the potent kinase activity by the BCR-ABL fusion protein [13-15].

As summarized by Meng and Huang [16] in this issue, Chinese scientists and physicians have also made great contributions to the fight against hematological malignancies, especially leukemia. A typical example is the effective applications of all-trans retinoic acid (ATRA, a vitamin A derivative) and arsenic trioxide (an ancient drug used in traditional Chinese medicine) in acute promyelocytic leukemia (APL, a subtype of acute myeloid leukemia (AML)), majority of which carry a chromosome translocation $\mathrm{t}(15 ; 17)$ expressing the oncogenic promyelocytic leukemia retinoic acid receptor-alpha (PML-RAR $\alpha$ ) fusion protein [17]. Both drugs cleave or degrade the fusion protein, where arsenic trioxide was shown to bind directly to cysteine residues in zinc fingers located within the RBCC domain of PMLRAR $\alpha$ and PML, inducing PML oligomerization and thus enhancing sumoylation and degradation of these two proteins [18]. On the other hand, ATRA selectively inhibits and degrades the active unique peptidyl-prolyl-isomerase Pin1 in cancer cells by directly binding to substrate phosphateand proline-binding pockets in its active site, and thereby degrading degrades the oncogenic PML-RAR $\alpha$ fusion protein [19].

Thalidomide, which was developed and sold as a sedative around 60 years ago but was soon banned because of its association with serious developmental defects, is being re-evaluated and is recognized as an effective treatment for myeloma [20,21]. Thalidomide derivatives including lenalidomide and pomalidomide have also been developed.
More recently, thalidomide and its derivatives have been shown to directly target the cereblon (CRBN) protein, a substrate-recognition component of an ubiquitin E3 ligase enzyme complex, promoting the degradation of the transcription factors Ikaros (IKZF1) and Aiolos (IKZF3), underlying the drugs' efficacy against myeloma [22,23]. Lenalidomide was also shown to be a highly effective treatment option for myelodysplastic syndrome (MDS) with deletions of chromosome 5q [24,25], a disorder of hematopoietic stem cells. Recently, Krönke et al. [26] reported that lenalidomide targets the CRBN protein to induce ubiquitination and degradation of casein kinase $1 \mathrm{~A} 1$, which is encoded by a gene within the common deleted region in $\operatorname{del}(5 q)$ MDS, providing a mechanistic basis for the therapeutic window of lenalidomide in $\operatorname{del}(5 q)$ MDS.

Inspired by these successful practices, many natural compounds were evaluated for their potential activities against hematological malignancies in the past decades [27,28]. Here we attempt to focus on several natural products that have shown anti-hematological malignancy activity and the identification of their potential targets.

\section{Adenanthin}

Diterpenoids, a large class of secondary metabolites isolated from plants, possess a wide spectrum of biological activities such as anti-tumor, anti-inflammation and significant cardiovascular effects $[29,30]$. Structurally, they can be classified into four groups including the ent-kauranes, ent-6,7secokauranes, ent-8,9-secokauranes and others (for more detail, see reference [30]). More than 600 diterpenoids have been identified in China thus far, some of these are abundant in plants such as Isodon (Rabdosia). Through our cooperation with professor Hang-Dong Sun's group in the State Key Laboratory of Phytochemistry and Plant Resources in West China, Kunming Institute of Botany, Chinese Academy of Sciences, we screened up to 400 natural ent-kaurene diterpenoids [31] for their potential antileukemic activities. We demonstrated that pharicin B, a natural ent-kaurane diterpenoid from the leaves of Isodon pharicus (a type of Chinese herbal plant found mainly in Tibet), can rapidly stabilize and enhance ATRA-dependent transcriptional activity of the RAR $\alpha$ protein, through which the natural product exhibits a synergistic or additive differentiation-enhancing effect with ATRA in several AML cell lines and some primary leukemic cells [32]. We also reported that pharicin A (Figure 1B), another ent-kaurene diterpenoid originally extracted from Isodon pharicus leaves, directly binds to BubR1 to induce mitotic arrest in leukemia and solid tumor-derived cells including chemotherapeutic drug paclitaxel-resistant malignant cells, and cells with unaligned chromosomes, aberrant BubR1 localization and deregulated spindle checkpoint activation [33]. Here we focus on the anti-leukemic activity of adenanthin 
and the identification of its targets. Adenanthin (Figure 1), a diterpenoid isolated from the leaves of Rabdosia adenantha [34], significantly decreases cell viability at a concentration of more than $4 \mu \mathrm{mol} \mathrm{L}{ }^{-1}$, while it also induces APL cells to undergo differentiation, independent of their sensitivity to ATRA [35]. Our further investigations showed that the adenanthin-induced differentiation can also be seen in primary leukemic blasts from the bone marrow of APL patients and in four of six newly diagnosed non-APL AML patients [36], suggesting that its differentiation-inducing effect is not restricted to APL. Applying isogenic B strain of Friend leukemia Virus (FVB/N) mice models with intravenous transplantation of ATRA-sensitive and ATRA- resistant leukemic blasts from transgenic mice expressing human PML-RAR $\alpha$ and its mutated form, we revealed that the intravenous administration of adenanthin $\left(5 \mathrm{mg} \mathrm{kg}^{-1}\right.$ body weight, each day for five consecutive days a week) significantly induces differentiation and tumor regression, and prolongs the survival of these two kinds of leukemic mice in spite of their sensitivity to ATRA [35]. Furthermore, adenanthin also significantly eliminates APL-initiating progenitor cells $\left(\mathrm{CD} 34^{+}, \mathrm{c}-\mathrm{kit}^{+}, \mathrm{Fc} \gamma \mathrm{RIII} / \mathrm{II}^{+}\right.$, and $\mathrm{Gr} 1^{\text {int }}$ ) in ATRA-sensitive leukemic mice [35]. All these results point to the potential therapeutic efficacy of adenanthin against AML.

Thus, we attempted to identify the potential target(s) for adenanthin's differentiation-inducing effect via a chemical proteomic approach $[35,36]$, similar to that summarized by Ziegler et al. [6]. For this purpose, a biotin-tagged adenanthin probe, which retained the ability to induce leukemic cell differentiation, was synthesized after establishing the structure-activity relationships of adenanthin. It was assumed that the $\alpha, \beta$-unsaturated moiety in adenanthin is a Michael acceptor that potentially captures nucleophiles such as cysteine (Cys) at its targeted binding site and forms covalent adducts, thus allowing for efficient protein recovery by the pull-down probe. Actually, reduction of the Michael acceptor double bond of adenanthin to a single bond abolished its in vitro and in vivo differentiation-inducing activity in leukemic cells (Figure 1), making it a suitable negative control. Thus, the NB4 APL cell line lysates were incubated with biotin-tagged adenanthin or free biotin, and the bound proteins were isolated with streptavidin-coated agarose beads, followed by sodium dodecyl sulfate-polyacrylamide gel electrophoresis and silver staining. The biotin-tagged adenanthin clearly precipitated only one detectable band at

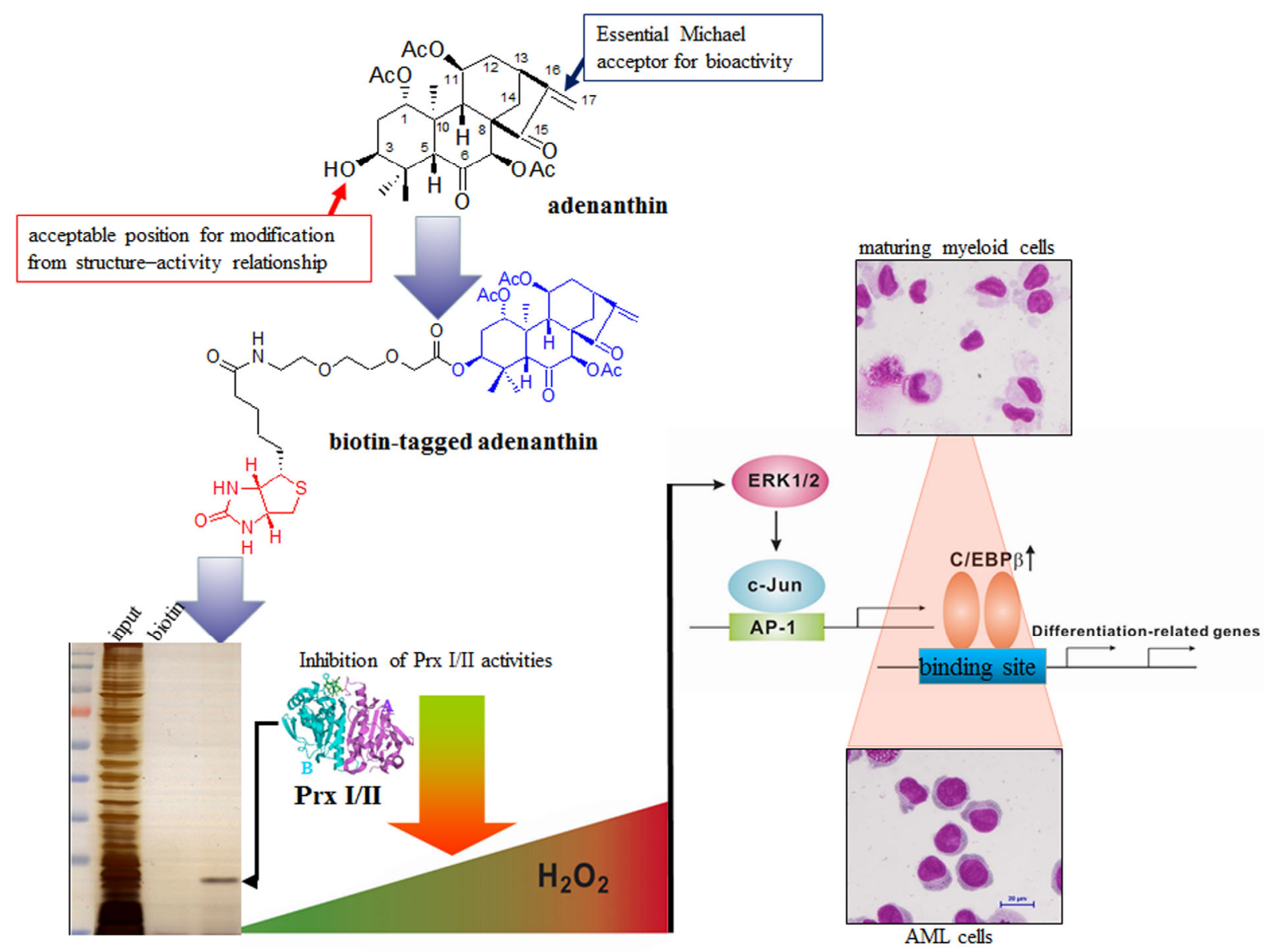

Figure 1 Structural formula of adenanthin and adenanthin-based pulldown probes as well as identification of its targets and molecular mechanism [6,35,36]. 
approximately $23 \mathrm{kD}$ (Figure 1), which was completely inhibited by high concentrations of unlabeled adenanthin, indicating a specific interaction. Mass spectrometry revealed that the adenanthin-bound protein is peroxiredoxin I and II (Prx I-II) [35].

Prxs, a family of small non-seleno peroxidases that catalyze peroxide reduction of reactive oxygen species (ROS, the most significant of which is hydrogen peroxide ), have drawn much interest because of their role as second messengers in cellular signaling pathways $[37,38]$. They have a conserved Cys residue (the peroxidatic $\mathrm{Cys}, \mathrm{C}_{\mathrm{P}}$ ) that serves as the site of oxidation by peroxides. Peroxides oxidize the $\mathrm{C}_{\mathrm{P}}-\mathrm{SH}$ to $\mathrm{C}_{\mathrm{P}}-\mathrm{SOH}$, which reacts with another $\mathrm{Cys}$ residue typically named resolving Cys $\left(\mathrm{C}_{\mathrm{R}}\right)$ to form a disulfide that is subsequently reduced by an appropriate electron donor. According to the location or absence of the $C_{R}$, the mammalian Prxs include 2-Cys (Prx I-IV), atypical 2-Cys (Prx V), and 1-Cys Prx (Prx VI) subfamilies [39]. Thus, we further blotted the precipitates with antibodies against all these six Prxs, all of which were expressed in NB4 cells, and demonstrated that biotin-tagged adenanthin pulled down cellular Prx I and II but not Prx IV-VI. Adenanthin also effectively bound to the in vitro recombinant Prx I and II proteins, an interaction that was competitively inhibited at high concentrations of unlabeled adenanthin but not by the negative control compound mentioned above. Moreover, biotin-tagged adenanthin co-localized with Prx I and II in the cytoplasm and nuclei of NB4 cells. Further investigations of mass spectrum-fragmentation patterns revealed selectivity for the Cys residues modified in Prx I and II, that is, the conserved $\mathrm{C}_{\mathrm{R}}$ of $\operatorname{Prx} \mathrm{I}\left(\mathrm{Cys}^{173}\right)$ or II protein $\left(\mathrm{Cys}^{172}\right)$ is the specific binding site for adenanthin. It remains to be investigated how adenanthin selectively binds to the specific Cys residues. Such a selective Cys binding action was recently reported for other natural compounds. For instance, a complex natural product ainsliadimer A selectively binds to the conserved $\mathrm{Cys}^{46}$ residue of I $\kappa \mathrm{B}$ kinase $\alpha / \beta$, leading to the inhibition of both canonical and non-canonical nuclear factor kappa-B (NF-кB) pathways [40].

Following binding to Prx I and II, adenanthin effectively inhibits the peroxidase activity of the recombinant Prx I/II protein. Accordingly, adenanthin treatment induced a moderate increase in intracellular $\mathrm{H}_{2} \mathrm{O}_{2}$ level. The concept has been proposed that modulation of the abundance of $\mathrm{H}_{2} \mathrm{O}_{2}$ is critical in regulating the balance between self-renewal and differentiation of hematopoietic stem cells [41]. Indeed, pre-treatment with $\mathrm{N}$-acetyl-l-cysteine, which effectively inhibits adenanthin-induced $\mathrm{H}_{2} \mathrm{O}_{2}$ accumulation, completely abrogated adenanthin-induced growth arrest and differentiation of APL cells. Our results further propose that the adenanthin-elevated $\mathrm{H}_{2} \mathrm{O}_{2}$ levels activate extracellular signal-regulated kinase (ERK) $1 / 2$ and subsequently leads to increased transcription of CCAAT/enhancer binding protein beta, which has been proven to induce differentiation of immature cells to granulocytes and monocytes (Figure 1).

Notably, we also showed that the Prx I protein is essential for the survival of hepatocellular carcinoma cells, and that adenanthin can kill these malignant liver cells in vitro and in xenografts by targeting Prx I/II [42]. However, the possibility could not be excluded that adenanthin might also bind with other protein(s). Actually, we showed that adenanthin exerts effective preventive and therapeutic effects on experimental autoimmune encephalomyelitis, which might be mediated via its inhibitory action on NF- $\kappa \mathrm{B}$ signaling pathway [43]. More recently, it was also shown that, next to Prx I/II, adenanthin also targets and inhibits the activity of additional proteins including the thioredoxin-thioredoxin reductase (TrxR) system and protein disulfide isomerase [44], as well as glutathione (GSH) [45]. However, Siernicka et al. [46] recently report that adenanthin only slightly reduces the total GSH in natural killer (NK) cells, which are considered critical components of the innate and adaptive immune responses as reviewed in this issue [47]. In the Siernicka et al.'s [46] report, they also show that adenanthin induces intracellular oxidative stress in human NK cells, with greater effects towards Prxs-related antioxidants rather than GSH-related defences. In spite of this, the interactions between adenanthin and Prx are crucial for proposing Prx as a therapeutic target for cancer [38]. Adenanthin and the recently identified Prxs-targeting compound theonellasterone [48], a steroidal metabolite isolated from a Theonella sponge, warrant further investigation for their anti-leukemia and anti-cancer activity.

\section{Oridonin}

Oridonin is also a natural ent-kaurane diterpenoid which was isolated in the 1970s from the Isodon plant Rabdosia rubescens (Donglingcao named in Chinese), a Chinese traditional medicinal herb commonly used for the treatment of sore throat, inflammation, and gastrointestinal problems in central China [49,50]. A series of in vitro studies showed that oridonin can inhibit the proliferation and/or induce apoptosis of cancer cells of various origins such as prostate cancer, breast cancer, non-small cell lung cancer, glioblastoma and human melanoma [51-54]. The cytokinetic effects of oridonin on murine leukemia cells were reported in the middle of the 1980s, furthering our understanding of its properties [55,56]. For the past ten years, the anti-leukemic effects of oridonin have been attracting greater interest. Zhou et al. [57] reported that oridonin induces apoptosis of AML cells carrying the chromosome translocation $\mathrm{t}(8 ; 21)$, which expresses the AML1-ETO fusion protein, and prolongs the lifespan of C57 mice bearing AML1-ETO-expressing leukemic cells. It also inhibits tumor growth in nude mice inoculated with 
$\mathrm{t}(8 ; 21)$-harboring leukemic Kasumi-1 cells. They further demonstrated that oridonin cleaves AML1-ETO to a catabolic fragment, which can be blocked by pre-incubation with caspase inhibitors, and that the ectopic expression of AML1-ETO enhances the apoptotic effect of oridonin in the non-AML1-ETO-carrying AML cell line U937. Mechanistically, oridonin interacts with glutathione and TrxR to increase intracellular ROS, which in turn activates caspase- 3 in $\mathrm{t}(8 ; 21)$-carrying AML cells. In addition, oridonin binds to the $\mathrm{Cys}^{347}$ of AML1-ETO, directing enzymatic cleavage at its aspartic acid 188 via caspase-3 to generate a truncated AML1-ETO ( $\triangle$ AML1-ETO) and preventing the protein from further proteolysis. The $\triangle$ AML1-ETO interacts with AML1-ETO and interferes with the trans-regulatory functions of the remaining AML1-ETO oncoprotein, thus acting as a tumor suppressor that mediates the anti-leukemia effect of oridonin [58]. These results show that oridonin is a potential lead compound for molecular target-based therapy of leukemia.

The anti-leukemic effects of oridonin do not appear to be restricted to $\mathrm{t}(8 ; 21)$-carrying AML cells. Actually, oridonin has also been shown to enhance leukemia cell differentiation or induce cell death in several other types of AML cells. Oridonin was also shown to kill some lymphoid malignancies, including multiple myeloma, adult T-cell leukemia and non-Hodgkin's lymphoma (NHL), possibly mediated by inhibition of the DNA-binding activ-

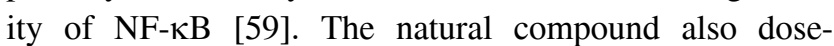
dependently induced apoptosis of the OCI-AML3 cell line harboring nucleophosmin (NPM) 1 mutations [60]. This is the most common genetic lesion in adult AML patients, accounting for $60 \%$ of cases with a normal karyotype and causes the skewed cytoplasmic accumulation of the NPM mutant protein $\left(\mathrm{NPM}_{1} \mathrm{c}^{+}\right.$), which is thought to be responsible for leukemia pathogenesis. The oridonin-induced apoptosis is accompanied by activation of caspase- 3 and nuclear translocation of the NPM1c ${ }^{+}$protein [60]. However, the direct target of oridonin responsible for the alteration of NPM1 mutant localization is currently unknown. Similar to pharicin B [32], oridonin enhances ATRAinduced cell differentiation in ATRA-sensitive NB4 and ATRA-resistant NB4-R1 cell lines [61], together with stabilization of RAR $\alpha$, which might be dependent on the mildly increased ROS and the subsequent activation of NF- $\kappa$ B [62]. Besides AML, Guo et al. [63] investigated the potential effects of oridonin on Philadelphia chromosome-positive acute lymphoblastic leukemia $\left(\mathrm{Ph}^{+} \mathrm{ALL}\right)$, which is triggered by constitutively activated BCR-ABL and Src family tyrosine kinases. They found that oridonin inhibits activation of Lyn (one of Src family kinases) and $\mathrm{ABL}$ and their downstream effectors in the Akt/mammalian target of rapamycin, Raf/mitogen-activated protein kinase kinase/ERK, and signal transducer and activator of transcription (STAT) 5 pathways. Oridonin also downregulates Bcl-2 but upregulates Bax protein, leading to apop- tosis of $\mathrm{Ph}^{+}$ALL cell line SUB-B15 cells and primary specimens from $\mathrm{Ph}^{+}$ALL patients.

Although oridonin appears effective in treating various kinds of malignant hematologic cancers, the underlying mechanism of oridonin is very complicated and its direct target is largely unclear. Similar to bioactive naturally occurring products such as eriocalyxin B [64] and adenanthin $[35,45]$, oridonin also contains an $\alpha, \beta$-unsaturated ketone in the D-ring, destruction of which abolishes its anticancer activity. The $\alpha, \beta$-unsaturated ketone, as a Michael acceptor, is an electrophilic center susceptible to nucleophilic attack (Michael addition) by a sulfhydryl group of reduced glutathione or cysteine residues in proteins, leading to adducts at the $\beta$-position. Thus, alkylation of crucial cysteine residues can result in a loss of function or activation of the target proteins. As mentioned above, oridonin can directly bind cleaved AML1-ETO at $\mathrm{Cys}^{347}$ [58] and TrxR [57,65]. TrxRs are essential proteins for regulating cellular redox balance and mitigating the damage caused by ROS. Inactivation of TrxR is a strategy to treat cancer through increasing the intracellular ROS level. In fact, a series of investigations have demonstrated that oridonin-induced cell death is associated with increased ROS production.

Dal Piaz et al. [66] recently used a chemical proteomic approach to identify the molecular chaperone heat shock protein (HSP) $701 \mathrm{~A}$ as an oridonin target in leukemic Jurkat cells. In detail, oridonin covalently binds to Cys ${ }^{267}$ of HSP70 1A and inhibits its activity. HSP70 is an ATP-dependent molecular chaperone that plays a key role in refolding misfolded proteins and promoting cell survival following stress. The chaperone is marginally expressed in nontransformed cells, but is greatly elevated in cancer cells. Silencing of Hsp70 is cytotoxic to tumor but not to normal cells, thus suggesting a mechanism of action for the diterpene consistent with its the multiple biological activities. HSP70 inhibition by oridonin might indeed result in impairment of some host proteins, thus affecting several molecular pathways. In particular, HSP70 inhibition could account for the effects of oridonin on the activity of mitogen-activated protein kinases, Akt, BAX, NF- $\kappa \mathrm{B}$ and caspases, since the functionality of these proteins depends on HSP70. Of note, Ye et al. [67] reported that vibsanin B, a novel macrocyclic diterpenoid isolated from Viburnum odoratissimum Ker-Gawl preferentially binds to HSP90 $\beta$ to inhibit interstitial leukocyte migration, thus ameliorating experimental autoimmune encephalomyelitis in mice.

Notably, leukemia cells resistant to chemotherapy-induced apoptosis have been found to be sensitive to oridonin. As an example, compared with HL60 cells, K562 and K562/ADR cells were resistant to apoptosis stimulated by Ara-C and VP-16, but were sensitive to the effects of oridonin. Mechanistic investigations revealed that oridonin upregulated BIM-S by diminishing the expression of miR-17 and miR-20a, leading to mitochondria-dependent 
apoptosis. In contrast, neither Ara-C nor VP-16 can reduce miR-17 and miR-20a expression or trigger BIM-Smediated apoptosis. Notably, silencing miR-17 or miR-20a expression by treatment with microRNA inhibitors or oridonin restored sensitivity of K562 cells to VP-16. The synergistic effects of oridonin and VP-16 were documented in cultured cells as well as mouse tumor xenograft assays [68].

\section{Gambogic acid}

Gambogic acid (GA) is a natural compound derived from the Chinese herb gamboges, which has been approved by the Chinese FDA for the treatment of different cancers in clinical trials [69]. Most recently, Liu's group reported that GA overcomes the drug-resistance of hematological malignancies, including CML with imatinib resistance and diffuse large B-cell lymphoma (DLBCL) resistant to R-CHOP (rituximab combined with cytoxan, hydroxyrubicin, oncovin, and prednisone). It is well known that the BCR-ABL T315I mutation is the predominant cause of resistance of CML cells to imatinib [70]. The emergence of imatinib resistance in patients with CML les to the search for novel approaches for its treatment. Liu's group [71] has investigated the antineoplastic effects of GA in CML cell lines, mononuclear cells from CML patients and in imatinib-resistant xenograft murine models. The results indicated that GA induces apoptosis together with cell proliferation inhibition in CML cells, including those cells harboring the BCR-ABL-T315I mutation, and primary mononuclear cells from CML patients resistant to imatinib. It also inhibits the growth of imatinib-resistant BCR-ABLT315I-carrying CML cell xenografts in nude mice.

DLBCL is an aggressive form of NHL. Resistance to the R-CHOP therapy regimen poses a great challenge to improving the survival of patients with DLBCL, especially those with activated B-cell-like DLBCL (ABCDLBCL) [72]. Therefore it is urgent to search for novel agents for the treatment of DLBCL. The Liu group [73] investigated the effect of GA on cell survival and apoptosis in DLBCL cells including both germinal center $B$ cell (GCB-)- and ABC-DLBCL cells. The results collectively demonstrated that $\mathrm{GA}$ has a significant effect against the GCB and ABC subtypes of DLBCL cells both in vitro and in vivo. The research provided the first demonstration that GA may have clinical benefit in patients with DLBCL, particularly in patients with ABC subtypes DLBCL.

Several potential molecular targets of GA have been reported, including binding to the transferrin receptor and suppressing the NF- $\mathrm{KB}$ signaling pathway [74], as well as inhibiting vascular endothelial growth factor receptor 2 [75]. However, its molecular targets have not been thoroughly studied. Liu's group [76] reported that GA inhibits tumor proteasome activity, with potency comparable to bortezomib, the first proteasome inhibitor approved for the treatment of multiple myeloma, but with less toxicity. Their results showed that GA gains the proteasomeinhibitory function after being metabolized by intracellular CYP2E1, that GA induced proteasome inhibition is a prerequisite for its cytotoxicity and anticancer action without off-target effects, and that the expression of the CYP2E1 gene is very high in tumor tissues but low in many normal tissues, and thus GA can produce tissue-specific proteasome inhibition and tumor-specific toxicity (Figure 2). Further, they showed that GA-induced proteasome inhibition and caspase activation are required for GA-induced BCR-ABL downregulation and cell apoptosis [71]. Judging by present reports, most current studies are mainly focused on finding tyrosine kinase inhibitors to either downregulate $\mathrm{BCR}-\mathrm{ABL}$ transcription or inhibit its tyrosine kinase activity. Here, the Liu group proposes an alternative strategy to enhance proteasome inhibition-induced BCR-ABL downregulation by activating the caspase system. Caspase-dependent BCR- ABL cleavage is effective both in KBM5-T315I cells and in the cancer cells from imatinib-resistant patients with CML, indicating that this strategy has a great promise in overcoming imatinib resistance.

\section{Wogonin and wogonoside}

Huang-Qin (Scutellaria baicalensis Georgi), one of the 50 fundamental herbs used in traditional Chinese medicine, is rich in flavonoids including wogonin (5,7-dihydroxy-8-

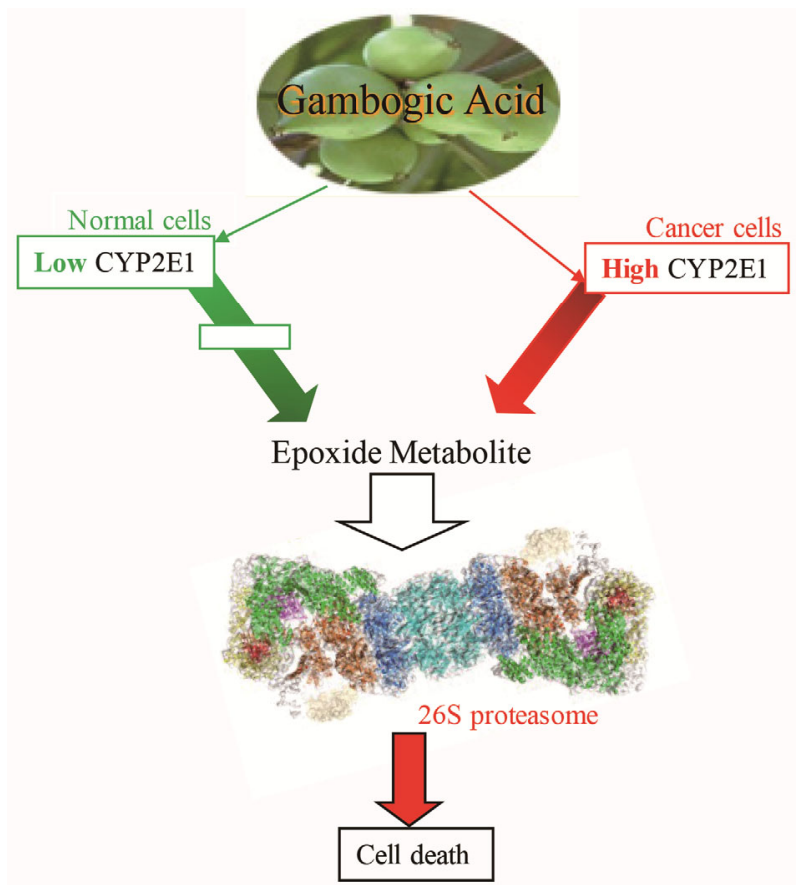

Figure 2 A schematic illustration of the mechanism for gambogic acid to induce cytotoxicity of cancer cells $[76,77]$. 
methoxy-2-phenyl-4H-chromen-4-one) [78-80]. In fact, these naturally-derived biologically active polyphenolic compounds are widely distributed in plants and relatively common in human diets. In the past decades, a series of in vitro and in vivo investigations showed that several structurally related flavonoids such as wogonin, luteolin, nobiletin and baicalein have multiple biological effects including anti-oxidant, anti-inflammatory, anti-viral, neuroprotective, anxiolytic, and anti-cancer activities [81-83]. Here we focused on the potential anti-leukemia effects of wogonin. It was shown that wogonin potently induces apoptotic cell death in leukemic HL-60 cells by increasing the expression of pro-apoptotic Bax protein and decreasing that of the anti-apoptotic myeloid cell leukemia 1 (Mcl-1) protein [84] and inhibiting the expression of human telomerase reverse transcriptase, telomerase-associated protein 1 and Myc mRNA, thereby down-regulating telomerase activity [85]. Recently, wogonin was also reported to induce the expression of certain members of the endoplasmic reticulum (ER) stress pathway and the activation of multiple branches of ER stress transducers, which are possibly mediated by the inhibition of the phosphoinositide 3-kinase/Akt signaling pathway [86]. Wogonin was also shown to induce cell cycle arrest at the $\mathrm{G}_{2} / \mathrm{M}$ phase and apoptosis of human monocytic leukemia cell line THP-1 but not that of the normal human fetal lung diploid cell line Tokyo Metropolitan Institute of Gerontology (TIG)-1 [87]. The following studies demonstrated that wogonin has almost no toxicity on $\mathrm{T}$ lymphocytes from healthy donors but that it induces apoptosis in malignant $\mathrm{T}$ cells in vitro and suppresses growth of human T-cell leukemia xenografts in vivo [88]. Mechanistically, wogonin induces prolonged activation of phospholipase $\mathrm{C} \gamma 1$ via $\mathrm{H}_{2} \mathrm{O}_{2}$ signaling, which leads to cytosolic $\mathrm{Ca}^{2+}$ overload and thus disruption of the mitochondrial membrane in malignant but not normal T cells [88]. Furthermore, wogonin and the structurally related natural flavones apigenin, chrysin and luteolin, bind directly to cyclin-dependent kinase 9 (CDK9) presumably to the ATP-binding pocket, and block phosphorylation of the carboxy-terminal domain of RNA polymerase II, leading to reduced RNA synthesis and subsequently rapid downregulation of the short-lived Mcl-1. Furthermore, wogonin preferentially inhibits CDK9 in malignant lymphocytes compared with normal lymphocytes $[89,90]$. More recently, an in vivo study with intraperitoneal injection of murine leukemia WEHI-3 cells into normal $\mathrm{BALB} / \mathrm{c}$ mice demonstrated that wogonin increases the survival rate and the body weight of leukemic mice by increasing the populations of T- and B-cells [91]. More surprisingly, wogonin displayed little apoptosis-inducing effect on human promyelocytic leukemia cell line NB4 cells, but continuous treatment of wogonin efficiently induces NB4 cells to undergo differentiation [92].

Flavonoid aglycones, which undergo rapid and extensive metabolism after either oral or intravenous admin- istration, enter the bloodstream in the form of glucuronide or sulfate conjugates. Very little unchanged aglycone can be found in the plasma, although there are high levels of glucuronic acid conjugates. Glucuronidation is thought to affect the biological activity of aglycones by altering the physicochemical properties of flavonoids, in what is considered a detoxification process [93]. Wogonin undergoes rapid metabolism and enters the bloodstream mainly in the form of the glucuronide wogonoside (Figure 1). As a metabolite of wogonin, wogonoside can also be derived from Scutellaria baicalensis Georgi. This wogonin derivative has been known to possess anti-inflammatory activity [94] and to inhibit lipopolysaccharide-induced angiogenesis in vitro and in vivo via toll-like receptor 4 signal transduction [95]. Wogonoside appears to have less toxicity to AML cells than wogonin does in vitro, in spite of no obvious difference in terms of acute in vivo toxicity. Therefore, it is interesting to investigate the potential effects of wogonoside on leukemic cells. Indeed, wogonoside exerts an in vitro antiproliferative activity in the AML cell lines U937, HL-60, and primary AML cells, and it inhibits the proliferation of U937 xenografts and prolongs survival in AML-bearing mice in vivo. Wogonoside-induced cell cycle arrest is associated with the downregulation of cyclin D1 and CDK4, and it also induces the differentiation of AML cell lines and primary AML cells [96].

Phospholipid scramblase 1 (PLSCR 1 ) is a calcium-binding, multiply palmitoylated type II endofacial plasma membrane protein, which is localized in either the cell membrane or nucleus depending on its palmitoylated state. In the nuclei, the unpalmitoylated PLSCR1 protein can bind to genomic DNA. Early research showed that PLSCR 1 contributes to the trans-bilayer movement of phospholipids, and the following studies revealed that PLSCR1 expression can be induced by some cytokines such as interferon, epidermal growth factor, and leukemic cell differentiation-inducing agents such as ATRA and phorbol 12-myristate 13-acetate [97,98]. Moreover, the induction of PLSCR1 transcription depends upon sequential activation of protein kinase $\mathrm{C}$ delta (PKC $\delta$ ), c-Jun $\mathrm{N}$-terminal kinases, and the phosphorylation of STAT1 at Ser-727 [99]. PLSCR1 was also shown to interact with several protein kinases including c-Abl, c-Src, PKC $\delta$ and onzin, suggesting a role of PLSCR1 in cell signaling [100-102]. Employinging an inducible PLSCR1expressing myeloid leukemia U937 cell line, we showed that inducible PLSCR1 expression arrests the proliferation at the $G_{1}$ phase and induces granulocyte-like differentiation with increased sensitivity to etoposide-induced apoptosis of the genetically engineered cells [103]. Of great interest is the fact that PLSCR1 expression can also be induced during wogonin and wogonoside-induced differentiation of AML-derived cell lines via dramatically increased $\mathrm{PKC} \delta$ phosphorylation at $\operatorname{Ser}^{643}[92,96]$. Moreover, p21 waf1/cip1 expression in wogonoside-treated cells increases at $48 \mathrm{~h}$ 
post-treatment, while conversely, the levels of c-Myc protein decrease upon exposure to wogonoside. The silencing of PLSCR1 by its sequence-specific siRNA blocks the wogonoside-induced increase in $\mathrm{p} 21^{\mathrm{waf} 1 / \mathrm{cip} 1}$ and decrease in c-Myc [96]. PLSCR1 was found inside the nuclei in U937 and HL-60 cells after treatment with wogonoside. It specifically binds to a segment of the 5 '-promoter of inositol 1,4,5-trisphosphate receptor 1 (IP3R1: ${ }^{-101}$ GTAACCATG$\mathrm{TGGA}^{-89}$ ), enhancing the transcription of this gene [104]. IP3R1 is known to play a key role in IP3-mediated mobilization of intracellular $\mathrm{Ca}^{2+}$ stores from the ER in a variety of cells and tissues, and it is also essential for cell growth and differentiation $[105,106]$. Wogonoside promotes nuclear PLSCR1 binding to the transcriptional activation domain of IP3R1 and increases IP3R1 protein expression. SiRNA against PLSCR1 effectively blocked the increased expression of IP3R1 when cells were cultured with wogonoside. Wogonoside thus appears to augment PLSCR1 expression at the transcriptional level and promotes its localization in the nucleus and its binding to the IP3R1 promoter, thus influencing the expression of this receptor. Cumulatively, wogonin and its metabolite wogonoside appear to be of therapeutic potential in leukemia, and their clinical effectiveness deserves to be further investigated.

\section{Conclusions}

Numerous naturally occurring small molecules from the plant kingdom have interesting properties against cancers, especially hematological malignancies. They might target different molecular regulatory pathways to interfere with the proliferation, differentiation, and death of hematological malignant cells or malignant hematopoietic stem/progenitor cells [8]. To date, the Dictionary of Natural Products has recorded approximately 200000 plant secondary metabolites, with about 170,000 unique structures. Approximately $15 \%$ of the drug interventions in the ClinicalTrials.gov database are plant-related, while about $60 \%$ of these drugs are sourced from plants [107]. In spite of these successes, the vast majority of plant species remain to be systematically investigated in drug discovery campaigns. In particular, bioactive compounds from herbs that are used in our traditional medicine still need to be more thoroughly explored, and the constant development of high-throughput functional assays and phenotypic screens in the omics era provides new opportunities for revival of interest in natural products for drug discovery.

Besides drug discovery, the use of bioactive small molecules will help to decipher and control life's processes, thus promoting our understanding of the molecular mechanisms of normal and abnormal cellular activities. Based on this, the term "chemical biology" has rightly been given to this thriving area at the interface of chemistry and biomedicine. In spite of its definition, the core element of chemi- cal biology is the use of exogenous chemistry (chemicals) to interrogate, modify, and manipulate biological systems at the cellular and organismal level in a highly controlled manner. From this view, chemicals offer opportunities usually not shared by classical genetic methods. On one hand, chemicals act rapidly such that the consequences of treatment with them can often be recorded after only minutes or seconds. Their effects are tunable and their influence is reversible, providing temporal control of protein function because the small molecules usually can be washed out or are metabolized. On the other hand, small bioactive molecules allow the targeting of proteins whose mutations, knock-out, or knock-down would be lethal. Moreover, chemicals can be used at any time point chosen for application. It is therefore crucial to identify and confirm the targets of bioactive small-molecules. In conclusion, scientists from biological, medicinal and chemical fields should come together to find more active compounds against hematological malignancies and to identify their targets.

The author(s) declare that they have no conflict of interest.

This work was supported by National Key Research Program of China (NO2015CB910403), and the National Natural Science Foundation (81230048, 81430061, 81272451).

1 Koehn FE, Carter GT. The evolving role of natural products in drug discovery. Nat Rev Drug Discov, 2005, 4: 206-220

2 Ji HF, Li XJ, Zhang HY. Natural products and drug discovery. Can thousands of years of ancient medical knowledge lead us to new and powerful drug combinations in the fight against cancer and dementia? EMBO Rep, 2009, 10: 194-200

3 Dias DA, Urban S, Roessner U. A historical overview of natural products in drug discovery. Metabolites, 2012, 2: 303-336

4 Chen J, Sun M, Wang X, Lu J, Wei Y, Tan Y, Liu Y, Gotz J, He R, Hua Q. The herbal compound geniposide rescues formaldehydeinduced apoptosis in N2a neuroblastoma cells. Sci China Life Sci, 2014, 57: 412-421

5 Newman DJ, Cragg GM. Natural products as sources of new drugs over the 30 years from 1981 to 2010. J Nat Prod, 2012, 75: 311-335

6 Ziegler S, Pries V, Hedberg C, Waldmann H. Target identification for small bioactive molecules: finding the needle in the haystack. Angew Chem Int Ed Engl, 2013, 52: 2744-2792

7 Doroghazi JR, Albright JC, Goering AW, Ju KS, Haines RR, Tchalukov KA, Labeda DP, Kelleher NL, Metcalf WW. A roadmap for natural product discovery based on large-scale genomics and metabolomics. Nat Chem Biol, 2014, 10: 963-968

8 Wang L, Chen G. Current advances in the application of proteomics in apoptosis research. Sci China Life Sci, 2011, 54: 209-219

9 Chen GQ, Zhang J, Zhao Q. Active compounds-based discoveries about the differentiation and apoptosis of leukemic cells. Chin Sci Bull, 2009, 54: 4094-4101

10 Wang Q, Cheng T. Evidences for mutations in the histone modifying gene SETD2 as critical drivers in leukemia development. Sci China Life Sci, 2014, 57: 944-946

11 Hamilton A, Gallipoli P, Nicholson E, Holyoake TL. Targeted therapy in haematological malignancies. J Pathol, 2010, 220: 404-418

12 Panjarian S, Iacob RE, Chen S, Engen JR, Smithgall TE. Structure 
and dynamic regulation of Abl kinases. J Biol Chem, 2013, 288: 5443-5450

13 Chereda B, Melo JV. Natural course and biology of CML. Ann Hematol, 2015, 94: S107-S121

14 Ben-Neriah Y, Daley GQ, Mes-Masson AM, Witte ON, Baltimore D. The chronic myelogenous leukemia-specific P210 protein is the product of the bcr/abl hybrid gene. Science, 1986, 233: 212-214

15 Yan H, Wang YC, Li D, Wang Y, Liu W, Wu YL, Chen GQ. Arsenic trioxide and proteasome inhibitor bortezomib synergistically induce apoptosis in leukemic cells: the role of protein kinase Cdelta. Leukemia, 2007, 21: 1488-1495

$16 \mathrm{Lv}$ M, Huang XJ. Fighting against hematological malignancy in china: from unique system to global impact. Sci China Life Sci, 2015, 58: 1183-1190

17 Tallman MS. Acute promyelocytic leukemia. Best Pract Res Clin Haematol, 2014, 27: 1

18 Zhang XW, Yan XJ, Zhou ZR, Yang FF, Wu ZY, Sun HB, Liang WX, Song AX, Lallemand-Breitenbach V, Jeanne M, Zhang QY, Yang HY, Huang QH, Zhou GB, Tong JH, Zhang Y, Wu JH, Hu HY, de The H, Chen SJ, Chen Z. Arsenic trioxide controls the fate of the PML-RARalpha oncoprotein by directly binding PML. Science, 2010, 328: 240-243

19 Wei S, Kozono S, Kats L, Nechama M, Li W, Guarnerio J, Luo M, You MH, Yao Y, Kondo A, Hu H, Bozkurt G, Moerke NJ, Cao S, Reschke M, Chen CH, Rego EM, Lo-Coco F, Cantley LC, Lee TH, Wu H, Zhang Y, Pandolfi PP, Zhou XZ, Lu KP. Active Pin1 is a key target of all-trans retinoic acid in acute promyelocytic leukemia and breast cancer. Nat Med, 2015, 21: 457-466

20 Ito T, Handa H. Myeloid disease: another action of a thalidomide derivative. Nature, 2015, 523: 167-168

21 Teo SK, Stirling DI, Zeldis JB. Thalidomide as a novel therapeutic agent: new uses for an old product. Drug Discov Today, 2005, 10: $107-114$

22 Kronke J, Udeshi ND, Narla A, Grauman P, Hurst SN, McConkey M, Svinkina T, Heckl D, Comer E, Li XY, Ciarlo C, Hartman E, Munshi N, Schenone M, Schreiber SL, Carr SA, Ebert BL. Lenalidomide causes selective degradation of IKZF1 and IKZF3 in multiple myeloma cells. Science, 2014, 343: 301-305

23 Lu G, Middleton RE, Sun H, Naniong M, Ott CJ, Mitsiades CS, Wong KK, Bradner JE, Kaelin WG, Jr. The myeloma drug lenalidomide promotes the cereblon-dependent destruction of ikaros proteins. Science, 2014, 343: 305-309

24 List A, Dewald G, Bennett J, Giagounidis A, Raza A, Feldman E, Powell B, Greenberg P, Thomas D, Stone R, Reeder C, Wride K, Patin J, Schmidt M, Zeldis J, Knight R. Lenalidomide in the myelodysplastic syndrome with chromosome $5 q$ deletion. N Engl J Med, 2006, 355: 1456-1465

25 List A, Kurtin S, Roe DJ, Buresh A, Mahadevan D, Fuchs D, Rimsza L, Heaton R, Knight R, Zeldis JB. Efficacy of lenalidomide in myelodysplastic syndromes. N Engl J Med, 2005, 352: 549-557

26 Krönke J, Fink EC, Hollenbach PW, MacBeth KJ, Hurst SN, Udeshi ND, Chamberlain PP, Mani DR, Man HW, Gandhi AK, Svinkina T, Schneider RK, McConkey M, Jaras M, Griffiths E, Wetzler M, Bullinger L, Cathers BE, Carr SA, Chopra R, Ebert BL. Lenalidomide induces ubiquitination and degradation of CK1alpha in del(5q) MDS. Nature, 2015, 523: 183-188

27 Morceau F, Chateauvieux S, Orsini M, Trecul A, Dicato M, Diederich M. Natural compounds and pharmaceuticals reprogram leukemia cell differentiation pathways. Biotechnol Adv, 2015, 33: 785-797

28 Robles-Fernandez I, Rodriguez-Serrano F, Alvarez PJ, Ortiz R, Rama AR, Prados J, Melguizo C, Alvarez-Manzaneda E, Aranega A. Antitumor properties of natural compounds and related molecules. Recent Pat Anticancer Drug Discov, 2013, 8: 203-215

29 Zhao Y, Niu XM, Qian LP, Liu ZY, Zhao QS, Sun HD. Synthesis and cytotoxicity of some new eriocalyxin B derivatives. Eur J Med Chem, 2007, 42: 494-502

30 Wang L, Li D, Wang C, Zhang Y, Xu J. Recent progress in the development of natural ent-kaurane diterpenoids with anti-tumor activity. Mini Rev Med Chem, 2011, 11: 910-919

31 Sun HD, Huang SX, Han QB. Diterpenoids from isodon species and their biological activities. Nat Product Rep, 2006, 23: 673-698

32 Gu ZM, Wu YL, Zhou MY, Liu CX, Xu HZ, Yan H, Zhao Y, Huang Y, Sun HD, Chen GQ. Pharicin B stabilizes retinoic acid receptor-alpha and presents synergistic differentiation induction with ATRA in myeloid leukemic cells. Blood, 2010, 116: 5289-5297

33 Xu HZ, Huang Y, Wu YL, Zhao Y, Xiao WL, Lin QS, Sun HD, Dai W, Chen GQ. Pharicin A, a novel natural ent-kaurene diterpenoid, induces mitotic arrest and mitotic catastrophe of cancer cells by interfering with BubR1 function. Cell Cycle, 2010, 9: 2897-2907

34 Jiang B, Yang H, Li ML, Hou AJ, Han QB, Wang SJ, Li SH, Sun HD. Diterpenoids from isodon adenantha. J Nat Prod, 2002, 65: $1111-1116$

35 Liu CX, Yin QQ, Zhou HC, Wu YL, Pu JX, Xia L, Liu W, Huang X, Jiang T, Wu MX, He LC, Zhao YX, Wang XL, Xiao WL, Chen HZ, Zhao Q, Zhou AW, Wang LS, Sun HD, Chen GQ. Adenanthin targets peroxiredoxin I and II to induce differentiation of leukemic cells. Nat Chem Biol, 2012, 8: 486-493

36 Liu CX, Zhou HC, Yin QQ, Wu YL, Chen GQ. Targeting peroxiredoxins against leukemia. Exp Cell Res, 2013, 319: 170-176

37 Schieber M, Chandel NS. ROS function in redox signaling and oxidative stress. Curr Biol, 2014, 24: R453-R462

38 Kang SW, Lee S, Lee EK. ROS and energy metabolism in cancer cells: alliance for fast growth. Arch Pharm Res, 2015, 38: 338-345

39 Wood ZA, Schroder E, Robin Harris J, Poole LB. Structure, mechanism and regulation of peroxiredoxins. Trends Biochem Sci, 2003, 28: $32-40$

40 Dong T, Li C, Wang X, Dian L, Zhang X, Li L, Chen S, Cao R, Huang $N$, He S, Lei X. Ainsliadimer A selectively inhibits IKKalpha/beta by covalently binding a conserved cysteine. Nat Commun, 2015, 6: 6522

41 Ye ZW, Zhang J, Townsend DM, Tew KD. Oxidative stress, redox regulation and diseases of cellular differentiation. Biochim Biophys Acta, 2014, 1850: 1607-1621

42 Hou JK, Huang Y, He W, Yan ZW, Fan L, Liu MH, Xiao WL, Sun $\mathrm{HD}$, Chen GQ. Adenanthin targets peroxiredoxin I/II to kill hepatocellular carcinoma cells. Cell Death Dis, 2014, 5: e1400

43 Yin QQ, Liu CX, Wu YL, Wu SF, Wang Y, Zhang X, Hu XJ, Pu JX, Lu Y, Zhou HC, Wang HL, Nie H, Sun HD, Chen GQ. Preventive and therapeutic effects of adenanthin on experimental autoimmune encephalomyelitis by inhibiting NF-kappaB signaling. J Immunol, 2013, 191: 2115-2125

44 Muchowicz A, Firczuk M, Chlebowska J, Nowis D, Stachura J, Barankiewicz J, Trzeciecka A, Klossowski S, Ostaszewski R, Zagozdzon R, Pu JX, Sun HD, Golab J. Adenanthin targets proteins involved in the regulation of disulphide bonds. Biochem Pharmacol, 2014, 89: 210-216

45 Soethoudt M, Peskin AV, Dickerhof N, Paton LN, Pace PE, Winterbourn CC. Interaction of adenanthin with glutathione and thiol enzymes: Selectivity for thioredoxin reductase and inhibition of peroxiredoxin recycling. Free Radic Biol Med, 2014, 77: 331-339

46 Siernicka M, Winiarska M, Bajor M, Firczuk M, Muchowicz A, Bobrowicz M, Fauriat C, Golab J, Olive D, Zagozdzon R. Adenanthin, a new inhibitor of thiol-dependent antioxidant enzymes, impairs the effector functions of human natural killer cells. Immunology, 2015, 146: 173-183

47 Li Y, Yin J, Li T, Huang S, Yan H, Leavenworth JM, Wang X. Natural killer cell based cancer immunotherapy: from basic biology to clinical application. Sci China Life Sci, 2015, 58: 1233-1245

48 Margarucci L, Monti MC, Tosco A, Esposito R, Zampella A, Sepe V, Mozzicafreddo M, Riccio R, Casapullo A. Theonellasterone, a steroidal metabolite isolated from a theonella sponge, protects peroxiredoxin-1 from oxidative stress reactions. Chem Commun (Camb), 2015, 51: 1591-1593

49 Zhou GB, Chen SJ, Wang ZY, Chen Z. Back to the future of oridonin: again, compound from medicinal herb shows potent 
antileukemia efficacies in vitro and in vivo. Cell Res, 2007, 17: 274-276

50 Zhao Z, Chen Y. Oridonin, a promising antitumor natural product in the chemotherapy of hematological malignancies. Curr Pharm Biotechnol, 2014, 15: 1083-1092

51 Gao FH, Hu XH, Li W, Liu H, Zhang YJ, Guo ZY, Xu MH, Wang ST, Jiang B, Liu F, Zhao YZ, Fang Y, Chen FY, Wu YL. Oridonin induces apoptosis and senescence in colorectal cancer cells by increasing histone hyperacetylation and regulation of p16, p21, p27 and c-myc. BMC Cancer, 2010, 10: 610

52 Liu Z, Ouyang L, Peng H, Zhang WZ. Oridonin: targeting programmed cell death pathways as an anti-tumour agent. Cell Prolif, 2012, 45: 499-507

53 Li X, Wang J, Ye Z, Li JC. Oridonin up-regulates expression of P21 and induces autophagy and apoptosis in human prostate cancer cells. Int J Biol Sci, 2012, 8: 901-912

54 Ikezoe T, Chen SS, Tong XJ, Heber D, Taguchi H, Koeffler HP. Oridonin induces growth inhibition and apoptosis of a variety of human cancer cells. Int J Oncol, 2003, 23: 1187-1193

55 Wang MY, Lin C, Zhang TM. Cytokinetic effects of oridonin on leukemia 11210 cells. Zhongguo Yao Li Xue Bao, 1985, 6: 195-198

56 Wang MY, Lin C, Zhang TM. effects of oridonin on DNA, RNA and protein syntheses of leukemia 11210 cells studied by autoradiography. Zhongguo Yao Li Xue Bao, 1987, 8: 164-165

57 Zhou GB, Kang H, Wang L, Gao L, Liu P, Xie J, Zhang FX, Weng XQ, Shen ZX, Chen J, Gu LJ, Yan M, Zhang DE, Chen SJ, Wang $Z Y$, Chen Z. Oridonin, a diterpenoid extracted from medicinal herbs, targets AML1-ETO fusion protein and shows potent antitumor activity with low adverse effects on $\mathrm{t}(8 ; 21)$ leukemia in vitro and in vivo. Blood, 2007, 109: 3441-3450

58 Zhen T, Wu CF, Liu P, Wu HY, Zhou GB, Lu Y, Liu JX, Liang Y, Li KK, Wang YY, Xie YY, He MM, Cao HM, Zhang WN, Chen LM, Petrie K, Chen SJ, Chen Z. Targeting of AML1-ETO in $t(8 ; 21)$ leukemia by oridonin generates a tumor suppressor-like protein. Sci Transl Med, 2012, 4: 127ra138

59 Ikezoe T, Yang Y, Bandobashi K, Saito T, Takemoto S, Machida H, Togitani K, Koeffler HP, Taguchi H. Oridonin, a diterpenoid purified from rabdosia rubescens, inhibits the proliferation of cells from lymphoid malignancies in association with blockade of the NF-kappa B signal pathways. Mol Cancer Ther, 2005, 4: 578-586

60 Li FF, Yi S, Wen L, He J, Yang LJ, Zhao J, Zhang BP, Cui GH, Chen Y. Oridonin induces NPM mutant protein translocation and apoptosis in NPM1c+ acute myeloid leukemia cells in vitro. Acta Pharmacol Sin, 2014, 35: 806-813

61 Gao F, Tang Q, Yang P, Fang Y, Li W, Wu Y. Apoptosis inducing and differentiation enhancement effect of oridonin on the all-trans-retinoic acid-sensitive and -resistant acute promyelocytic leukemia cells. Int J Lab Hematol, 2010, 32: e114-e122

62 Cao Y, Wei W, Zhang N, Yu Q, Xu WB, Yu WJ, Chen GQ, Wu YL, Yan H. Oridonin stabilizes retinoic acid receptor alpha through ROS-activated NF-kappaB signaling. BMC Cancer, 2015, 15: 248

63 Guo Y, Shan Q, Gong Y, Lin J, Yang X, Zhou R. Oridonin in combination with imatinib exerts synergetic anti-leukemia effect in $\mathrm{Ph}^{+}$acute lymphoblastic leukemia cells in vitro by inhibiting activation of LYN/mTOR signaling pathway. Cancer Biol Ther, 2012, 13: 1244-1254

64 Li L, Yue GG, Pu JX, Sun HD, Fung KP, Leung PC, Han QB, Lau $\mathrm{CB}$, Leung PS. Eriocalyxin B-induced apoptosis in pancreatic adenocarcinoma cells through thiol-containing antioxidant systems and downstream signalling pathways. Curr Mol Med, 2014, 14: 673-689

65 Gao FH, Liu F, Wei W, Liu LB, Xu MH, Guo ZY, Li W, Jiang B, $\mathrm{Wu}$ YL. Oridonin induces apoptosis and senescence by increasing hydrogen peroxide and glutathione depletion in colorectal cancer cells. Int J Mol Med, 2012, 29: 649-655

66 Dal Piaz F, Cotugno R, Lepore L, Vassallo A, Malafronte N, Lauro G, Bifulco G, Belisario MA, De Tommasi N. Chemical proteomics reveals HSP70 1A as a target for the anticancer diterpene oridonin in Jurkat cells. J Proteomics, 2013, 82: 14-26
67 Ye BX, Deng X, Shao LD, Lu Y, Xiao R, Liu YJ, Jin Y, Xie YY, Zhao Y, Luo LF, Ma S, Gao M, Zhang LR, He J, Zhang WN, Chen Y, Xia CF, Deng M, Liu TX, Zhao QS, Chen SJ, Chen Z. Vibsanin B preferentially targets HSP90beta, inhibits interstitial leukocyte migration, and ameliorates experimental autoimmune encephalomyelitis. J Immunol, 2015, 194: 4489-4497

68 Weng H, Huang H, Dong B, Zhao P, Zhou H, Qu L. Inhibition of miR-17 and miR-20a by oridonin triggers apoptosis and reverses chemoresistance by derepressing BIM-S. Cancer Res, 2014, 74: 4409-4419

69 Zhou ZT, Wan JW. Phase I human tolerability trial of gambogic acid. Chin J New Drugs, 2007, 1: 679-682

70 Shi XP, Jin YL, Cheng C, Zhang H, Zou WY, Zheng Q, Lu ZZ, Chen Q, Lai YR, Pan JX. Triptolide inhibits Bcr-Abl transcription and induces apoptosis in STI571-resistant chronic myelogenous leukemia cells harboring T315I mutation. Clin Cancer Res, 2009, 15: 1686-1697

71 Shi X, Chen X, Li X, Lan X, Zhao C, Liu S, Huang H, Liu N, Liao S, Song W, Zhou P, Wang S, Xu L, Wang X, Dou QP, Liu J. Gambogic acid induces apoptosis in imatinib-resistant chronic myeloid leukemia cells via inducing proteasome inhibition and caspase-dependent Bcr-Abl downregulation. Clin Cancer Res, 2014, 20: $151-163$

72 Cvetković RS, Perry CM. Rituximab: a review of its use in non-Hodgkin's lymphoma and chronic lymphocytic leukaemia. Drugs, 2006, 66: 791-820

73 Shi X, Lan X, Chen X, Zhao C, Li X, Liu S, Huang H, Liu N, Zang D, Liao Y, Zhang P, Wang X, Liu J. Gambogic acid induces apoptosis in diffuse large B-cell lymphoma cells via inducing proteasome inhibition. Sci Rep, 2015, 5: 9694

74 Pandey MK, Sung B, Ahn KS, Kunnumakkara AB, Chaturvedi MM, Aggarwal BB. Gambogic acid, a novel ligand for transferrin receptor, potentiates tnf-induced apoptosis through modulation of the nuclear factor-kappaB signaling pathway. Blood, 2007, 110: $3517-3525$

75 Yi T, Yi Z, Cho SG, Luo J, Pandey MK, Aggarwal BB, Liu M. Gambogic acid inhibits angiogenesis and prostate tumor growth by suppressing vascular endothelial growth factor receptor 2 signaling. Cancer Res, 2008, 68: 1843-1850

76 Li XF, Liu ST, Huang HB, Liu NN, Zhao C, Liao SY, Yang CS, Liu YR, Zhao CG, Li SJ, Lu XY, Liu CJ, Guan LX, Zhao K, Shi XQ, Song WB, Zhou P, Dong XX, Guo HP, Wen GM, Zhang CG, Jiang LL, Ma NF, Li B, Wang SQ, Tan H, Wang XJ, Dou QP, Liu JB. Gambogic acid is a tissue-specific proteasome inhibitor in vitro and in vivo. Cell Rep, 2013, 3: 211-222

77 da Fonseca PC, He J, Morris EP. Molecular model of the human 26S proteasome. Mol Cell, 2012, 46: 54-66

78 He L, Lu N, Dai Q, Zhao Y, Zhao L, Wang H, Li Z, You Q, Guo Q. Wogonin induced G1 cell cycle arrest by regulating Wnt/beta-catenin signaling pathway and inactivating CDK8 in human colorectal cancer carcinoma cells. Toxicology, 2013, 312: $36-47$

79 Chirumbolo S. Anticancer properties of the flavone wogonin. Toxicology, 2013, 314: 60-64

80 Han J, Ye M, Xu M, Sun J, Wang B, Guo D. Characterization of flavonoids in the traditional chinese herbal medicine-huangqin by liquid chromatography coupled with electrospray ionization mass spectrometry. J Chromatogr B Analyt Technol Biomed Life Sci, 2007, 848: 355-362

81 Lopez-Lazaro M. Distribution and biological activities of the flavonoid luteolin. Mini Rev Med Chem, 2009, 9: 31-59

82 Yanagihara N, Zhang H, Toyohira Y, Takahashi K, Ueno S, Tsutsui $\mathrm{M}$, Takahashi $\mathrm{K}$. New insights into the pharmacological potential of plant flavonoids in the catecholamine system. J Pharmacol Sci, 2014, 124: 123-128

83 Li-Weber M. New therapeutic aspects of flavones: the anticancer properties of scutellaria and its main active constituents wogonin, baicalein and baicalin. Cancer Treatment Rev, 2009, 35: 57-68

84 Lee WR, Shen SC, Lin HY, Hou WC, Yang LL, Chen YC. 
Wogonin and fisetin induce apoptosis in human promyeloleukemic cells, accompanied by a decrease of reactive oxygen species, and activation of caspase 3 and $\mathrm{Ca}^{2+}$-dependent endonuclease. Biochem Pharmacol, 2002, 63: 225-236

85 Huang ST, Wang CY, Yang RC, Chu CJ, Wu HT, Pang JH. Wogonin, an active compound in Scutellaria baicalensis, induces apoptosis and reduces telomerase activity in the HL-60 leukemia cells. Phytomedicine, 2010, 17: 47-54

$86 \mathrm{Hu} \mathrm{C}, \mathrm{Xu} \mathrm{M}$, Qin R, Chen W, Xu X. Wogonin induces apoptosis and endoplasmic reticulum stress in HL-60 leukemia cells through inhibition of the PI3K-AKT signaling pathway. Oncol Rep, 2015, 33: 3146-3454

87 Himeji M, Ohtsuki T, Fukazawa H, Tanaka M, Yazaki S, Ui S, Nishio K, Yamamoto H, Tasaka K, Mimura A. Difference of growth-inhibitory effect of scutellaria baicalensis-producing flavonoid wogonin among human cancer cells and normal diploid cell. Cancer Lett, 2007, 245: 269-274

88 Baumann S, Fas SC, Giaisi M, Muller WW, Merling A, Gulow K, Edler L, Krammer PH, Li-Weber M. Wogonin preferentially kills malignant lymphocytes and suppresses T-cell tumor growth by inducing PLCgamma1- and $\mathrm{Ca}^{2+}$-dependent apoptosis. Blood, 2008 , 111: 2354-2363

89 Polier G, Ding J, Konkimalla BV, Eick D, Ribeiro N, Kohler R, Giaisi M, Efferth T, Desaubry L, Krammer PH, Li-Weber M. Wogonin and related natural flavones are inhibitors of CDK9 that induce apoptosis in cancer cells by transcriptional suppression of Mcl-1. Cell Death Disease, 2011, 2: e182

90 Polier G, Giaisi M, Kohler R, Muller WW, Lutz C, Buss EC, Krammer $\mathrm{PH}$, Li-Weber M. Targeting CDK9 by wogonin and related natural flavones potentiates the anti-cancer efficacy of the Bcl-2 family inhibitor ABT-263. Int J Cancer, 2015, 136: 688-698

91 Lin CC, Lin JJ, Wu PP, Lu CC, Chiang JH, Kuo CL, Ji BC, Lee $\mathrm{MH}$, Huang AC, Chung JG. Wogonin, a natural and biologically-active flavonoid, influences a murine WEHI-3 leukemia model in vivo through enhancing populations of T- and B-cells. In Vivo, 2013, 27: 733-738

92 Zhang HW, Yang Y, Zhang K, Qiang L, Yang L, Hu Y, Wang XT, You QD, Guo QL. Wogonin induced differentiation and G1 phase arrest of human U-937 leukemia cells via PKCdelta phosphorylation. Eur J Pharmacol, 2008, 591: 7-12

93 Hollman PC, Katan MB. Absorption, metabolism and health effects of dietary flavonoids in man. Biomed Pharmacother, 1997, 51: 305-310

94 Lim BO. Effects of wogonin, wogonoside, and 3,5,7,2',6'pentahydroxyflavone on chemical mediator production in peritoneal exduate cells and immunoglobulin $\mathrm{E}$ of rat mesenteric lymph node lymphocytes. J Ethnopharmacol, 2003, 84: 23-29

95 Chen Y, Lu N, Ling Y, Gao Y, Wang L, Sun Y, Qi Q, Feng F, Liu
W, You Q, Guo Q. Wogonoside inhibits lipopolysaccharide-induced angiogenesis in vitro and in vivo via toll-like receptor 4 signal transduction. Toxicology, 2009, 259: 10-17

96 Chen Y, Hui H, Yang H, Zhao K, Qin Y, Gu C, Wang X, Lu N, Guo Q. Wogonoside induces cell cycle arrest and differentiation by affecting expression and subcellular localization of PLSCR1 in AML cells. Blood, 2013, 121: 3682-3691

97 Huang Y, Zhao Q, Chen GQ. Phospholipid scramblase 1. Sheng Li Xue Bao, 2006, 58: 501-510

98 Zhao KW, Li X, Zhao Q, Huang Y, Li D, Peng ZG, Shen WZ, Zhao J, Zhou Q, Chen Z, Sims PJ, Wiedmer T, Chen GQ. Protein kinase cdelta mediates retinoic acid and phorbol myristate acetate-induced phospholipid scramblase 1 gene expression: its role in leukemic cell differentiation. Blood, 2004, 104: 3731-3738

99 Zhao KW, Li D, Zhao Q, Huang Y, Silverman RH, Sims PJ, Chen GQ. Interferon-alpha-induced expression of phospholipid scramblase 1 through STAT1 requires the sequential activation of protein kinase Cdelta and JNK. J Biol Chem, 2005, 280: 42707-42714

100 Li Y, Rogulski K, Zhou Q, Sims PJ, Prochownik EV. The negative c-Myc target onzin affects proliferation and apoptosis via its obligate interaction with phospholipid scramblase 1. Mol Cell Biol, 2006, 26: 3401-3413

101 Wu SF, Huang Y, Hou JK, Yuan TT, Zhou CX, Zhang J, Chen GQ. The downregulation of onzin expression by PKCepsilon-ERK2 signaling and its potential role in AML cell differentiation. Leukemia, 2010, 24: 544-551

102 Kodigepalli KM, Bowers K, Sharp A, Nanjundan M. Roles and regulation of phospholipid scramblases. FEBS Lett, 2015, 589: $3-14$

103 Huang Y, Zhao Q, Zhou CX, Gu ZM, Li D, Xu HZ, Wiedmer T, Sims PJ, Zhao KW, Chen GQ. Antileukemic roles of human phospholipid scramblase 1 gene, evidence from inducible PLSCR1expressing leukemic cells. Oncogene, 2006, 25: 6618-6627

104 Zhou Q, Ben-Efraim I, Bigcas JL, Junqueira D, Wiedmer T, Sims PJ. Phospholipid scramblase 1 binds to the promoter region of the inositol 1,4,5-triphosphate receptor type 1 gene to enhance its expression. J Biol Chem, 2005, 280: 35062-35068

105 Mikoshiba K. IP3 receptor/Ca ${ }^{2+}$ channel: from discovery to new signaling concepts. J Neurochem, 2007, 102: 1426-1446

106 Acharya JK, Jalink K, Hardy RW, Hartenstein V, Zuker CS. InsP3 receptor is essential for growth and differentiation but not for vision in Drosophila. Neuron, 1997, 18: 881-887

107 Harvey AL, Edrada-Ebel R, Quinn RJ. The re-emergence of natural products for drug discovery in the genomics era. Nat Rev Drug Discov, 2015, 14: 111-129

Open Access This article is distributed under the terms of the Creative Commons Attribution License which permits any use, distribution, and reproduction in any medium, provided the original author(s) and source are credited. 